\title{
Site wiki em sala de aula: uma experiência com hipertextualidade
}

Mayra Rodrigues Gomes

Professora doutora, livre-docente, do Departamento de Jornalismo e Editoração da Escola de Comunicaşão e Artes da Universidade de São Paulo (ECA-USP)'.

E-mail:mayragomes@usp.br

Resumo: Este artigo versa sobre a adoção da ferramenta wiki, em disciplinas dedicadas a teorias da linguagem, com a finalidade de estimular a pesquisa e introduzir os alunos a recursos diversificados, por meio do trabalho em ambiente hipertextual. Após dois anos de aplicação, relatamos observações sobre a produção de textos em sites wikis construídos para alunos de graduação em Jornalismo.

Palavras-chave: ferramenta wiki, interatividade, hipertexto.
Abstract: This paper is about the adoption of the wiki resource, in courses dedicate to language theories, aiming to encourage research and to present diversified resources to the students, with the work in hypertext ambiance. After two years of application, we present the observations about text production in wiki sites installed for under-graduated students of journalism.

Keywords: wiki resource, interactivity, hypertext.

Em 2007, a revista Comunicação \& Educação publicou artigo intitulado A ferramenta wiki: uma experiência pedagógica ${ }^{2}$, em que descrevíamos um projeto, em sua primeira etapa, de instalação do site wiki para disciplinas do curso de Jornalismo e Editoração da ECA-USP.

Relembrando, o software wiki é um gerenciador de conteúdo que permite a construção colaborativa, como tem sido desenvolvida, por exemplo, pela Wikipédia. Por isso, convida, naturalmente, à organização hipertextual. Entendemos esse processo enquanto dinâmica que incorpora e agrega meios diferenciados, como texto e imagem, podendo remeter, com a inserção de links, a outras produções e produtos.

Contamos com a colaboração da orientanda de doutorado Andrea Limberto Leite quanto à instalação, supervisão dos sites e monitoria junto às disciplinas para as quais os sites são construídos. No site wiki criado para cada classe, período matutino e noturno de cada ano, os alunos compõem os trabalhos/ artigos como requisitos para avaliação final nas disciplinas. Estas têm cunho teórico, voltado ao estudo de propriedades, pensadores e suas teorias, assim como procedimentos metodológicos ligados ao campo das linguagens.

Recebido: 21.01 .2008

Aprovado: 04.03 .2008

1. Disponível em: $<$ http://lattes.cnpq.br /8147720106880868>.

2. GOMES, Mayra Rodrigues. A ferramenta wiki: uma experiência pedagógica. Comunicação \& Educação, São Paulo, CCA-ECA-USP, ano XII, $n$. 2, maio/ago. 2007. 
Organizadas em módulos sob a rubrica Ciências da Linguagem, as disciplinas são parcialmente compartilhadas com a Profa. Dra. Rosana de Lima Soares. Têm, como um de seus objetivos, promover a reflexão, por parte dos alunos, sobre a produção midiática em geral. Esse exercício deve fundamentar-se na aplicação dos conceitos teóricos examinados ao longo do percurso programático, tarefa que se concretiza com a construção dos trabalhos finais antes mencionados.

No wiki, as conexões estabelecidas pela colocação de links tanto podem ser realizadas com os textos dos colegas de classe, portanto internamente ao próprio site criado para a turma, quanto podem compreender ligações a toda e qualquer produção presente na www - world wide web, que em português significa rede de alcance mundial. Pretendíamos, em virtude das propriedades da ferramenta, estimular a produção cooperativa e a criatividade, convidar à pesquisa sobre temas e conceitos teóricos, para além dos textos recomendados durante o curso, e refletir, com os alunos, sobre os meandros da produção em hipertexto.

Esta proposta de trabalho transformou-se em projeto de pesquisa sob o título Labirintos textuais: investigação dos caminhos para a incorporação da ferramenta wiki em sala de aula, com apoio do CNPq.

As produções hipertextuais obtidas foram observadas sob o foco das intenções mencionadas, aliado ao método de aferição por confronto, no caso, entre os produtos de um semestre a outro, e de um ano ao seguinte, circunscritos ao período que vai de março de 2006 a dezembro de 2007. Destas observações brotam os resultados, sempre em relação a nossos propósitos, que descreveremos mais adiante. O período de aplicação compreende duas turmas de alunos a cada ano, matutino e noturno, e dois módulos das disciplinas em que se aplica o projeto em site wiki, a saber, os módulos I e II, sendo que o I não é compartilhado com outro docente.

Além da criação de site wiki para cada turma, adotamos algumas diretrizes, que funcionaram tanto para 2006 quanto para 2007, visando à melhor condução dos trabalhos e das condições de sua avaliação. Aos leitores deste texto, que porventura queiram aplicar o wiki em sala de aula, apontamos estas diretrizes como um modo, dentre os muitos possibilitados pela ferramenta, de administrar um campo de trabalho. Tal administração é necessária porque o site wiki é de total abertura, permitindo a interferência de uma autoria sobre outra, assim como a proliferação indiscriminada de textos e páginas.

Para os primeiros semestres, determinamos uma produção colaborativa a partir da construção de uma página principal para cada turma. Nela se inscreveram 10 temas diferentes correspondentes a 10 grupos de alunos. Cada um dos temas vincula-se aos conteúdos da disciplina ministrada, embora tenham sido escolhidos e rubricados pelos próprios alunos. Os nomes dos alunos pertencentes a um grupo são assinados logo após a rubrica do tema que é, ao mesmo tempo, a do grupo. Esta, transformada em link, remete a outra página, agora específica do grupo, onde se constrói o texto colaborativo solicitado. 
A seguir, apresentamos parte da construção de uma página principal em 2007, lembrando que cada rubrica do grupo de alunos corresponde a um link para outra página, que poderíamos chamar de principal em relação ao grupo.

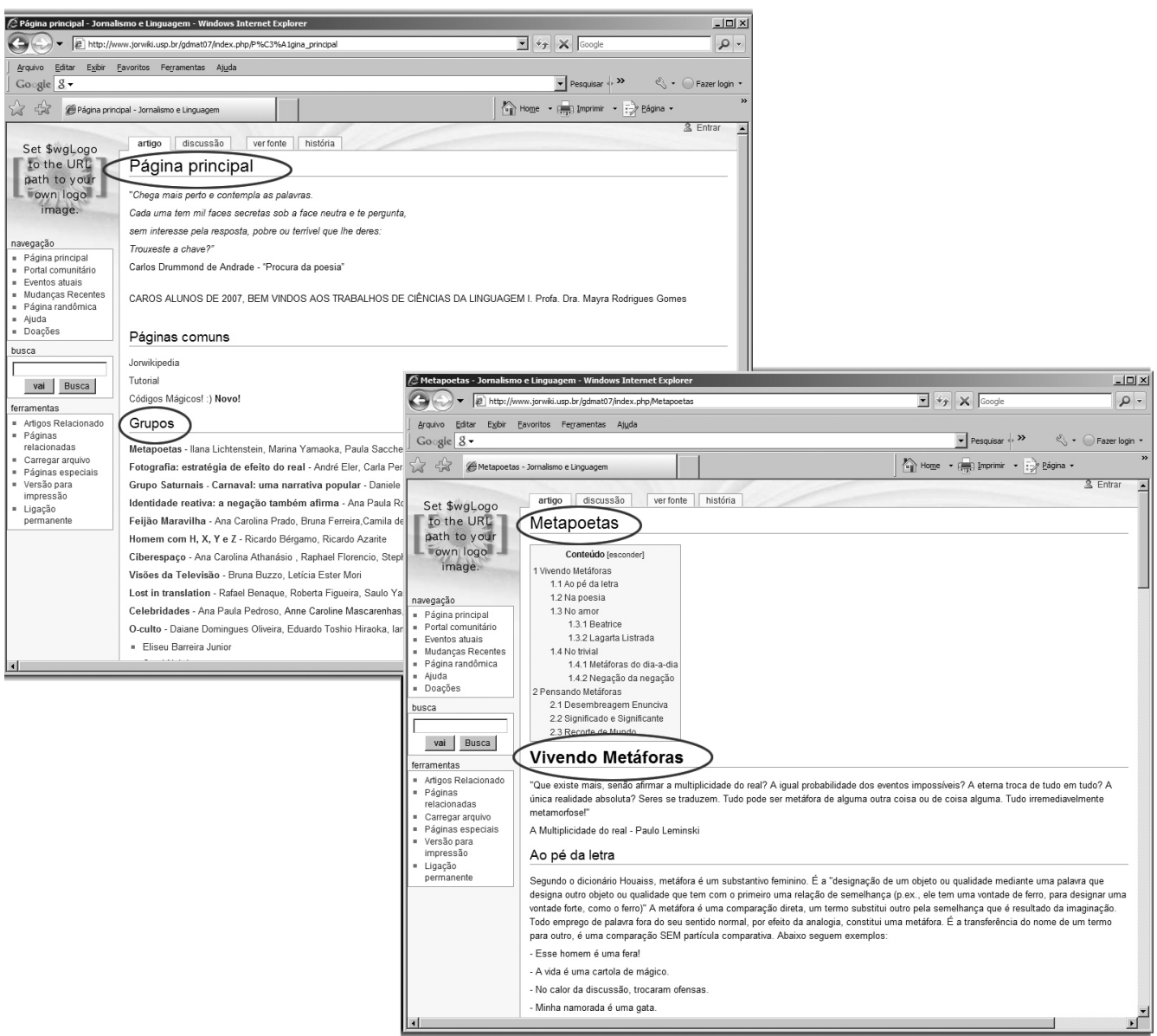

Tela de captura do site, com a página principal. No destaque, a página inicial do trabalho/artigo do primeiro grupo listado, aquele sob a rubrica "Metapoetas".

Ao longo dos primeiros semestres, os trabalhos prosseguiram com o desenvolvimento de links externos e internos, e a inclusão de imagens, com o refinamento de temas e aportes teóricos escolhidos por grupo.

Nos segundos semestres, abandonamos o texto colaborativo e solicitamos a composição de texto/trabalho individual. O trabalho devia ser acoplado ao seu autor, já inscrito em um dos grupos formados no primeiro semestre. Cada um construiu, a partir do link com seu nome, uma página de texto na qual produziu artigo a ser avaliado como trabalho final na disciplina.

Novamente, além de solicitado o exercício com as propriedades da ferramenta wiki, pedimos que o trabalho discorresse sobre assuntos ao gosto do aluno, mas explorados sob a perspectiva dos conceitos teóricos estudados na disciplina. 
3. Período matutino: $<$ http://www.jorwiki.usp. $\mathrm{br} / \mathrm{gdmat} 06>$. Período noturno: <http://www. jorwiki.usp.br/gdnot06>.

4. Período matutino: $<$ http://www.jorwiki.usp. $\mathrm{br} / \mathrm{gdmat} 07>$. Período noturno: <http://www. jorwiki.usp.br/gdnot07>.

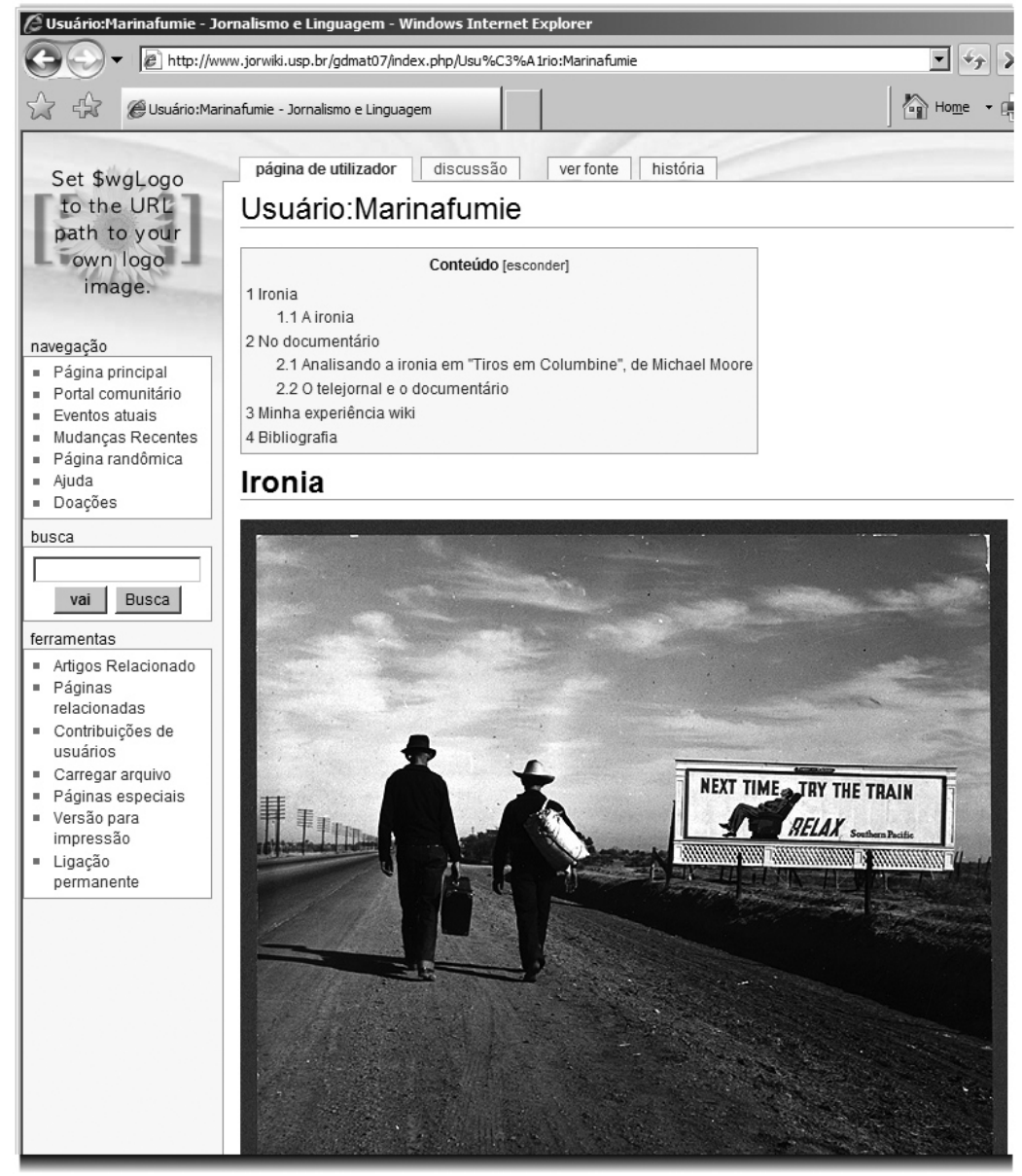

A título de exemplo, o início da página/trabalho da aluna Marina Yamaoka, inscrita no grupo "Metapoetas", o primeiro da página principal construída no primeiro semestre.

Após dois anos e meio de trabalhos com site wiki, apresentamos nossas observações em relação às expectativas anunciadas. Além de compararmos, como já anunciamos, a produção de um semestre com a do seguinte, e a de $2006^{3}$ com a de $2007^{4}$, levamos em conta, também, as observações dos alunos sobre a experiência de produção de texto nesse ambiente.

\section{ANOTAÇÕES: A RELAÇÃO ENTRE PRIMEIROS E SEGUNDOS SEMESTRES, ENTRE A PRODUÇÃO DE 2006 E A DE 2007}

Quanto à produção dos primeiros semestres, podemos dizer que ela é tímida em relação à dos segundos e, quantitativamente, esta observação se estende a todos os trabalhos, até mesmo àqueles que se destacaram por conta de um empenho maior dos alunos. Esta contingência nos é revelada ao constatarmos que há menor aproveitamento das opções de construção textual. Muito contribui para esta ocorrência o fato de que os alunos sentem desconforto, por 
não estarem familiarizados com a ferramenta wiki e tampouco com o trabalho colaborativo, em termos da própria criação de texto.

Percebemos que a primeira dificuldade está associada ao medo genérico de lidar com computador e softwares, comum entre muitas pessoas. Esta dificuldade é superada com o passar do tempo, à medida que os alunos compreendem melhor as propriedades da ferramenta wiki e alcançam habilidade em seu manuseio. Quanto a esta questão, adiantamos nossas anotações e trazemos o testemunho dos próprios alunos, que só é emitido ao final dos segundos semestres. Muitos declararam que o trabalho em site wiki fez com perdessem o medo de lidar com novos recursos digitais.

Em relação à dificuldade com textos colaborativos, os alunos encontraram soluções que, no entanto, remetem a uma fragmentação do texto, pois uma grande parte dividiu as tarefas entre os membros do grupo. Alguns ficaram responsáveis pela redação do texto, enquanto aos outros coube as tarefas de inserção de links e de revisão. Também houve divisão em relação ao conteúdo, de forma que cada membro do grupo se dedicava a uma faceta do trabalho.

Percebemos que a etapa mais colaborativa se encontra nas tomadas de decisão sobre o tema e seus enfoques, assim como nos modos de manutenção da coerência e da coesão textual. Embora nem sempre todos concordassem com os direcionamentos dados, um consenso foi alcançado para que o trabalho chegasse a bom termo. No geral, podemos dizer que, em relação à própria redação, o nível de colaboração ficou aquém do esperado devido à adoção da divisão de tarefas.

Os textos individuais dos segundos semestres são mais extensos, às vezes se desdobrando em novas páginas, fato que implica maior exploração do tema escolhido. São, igualmente, mais criativos, se considerarmos que os alunos começam a importar propriedades de outras ferramentas para a wiki, ou seja, passam a inventar. Por outro lado, apresentam-se mais rebuscados com relação ao desenvolvimento da temática, procurando dar conta de vieses inusitados quanto ao conteúdo programático. Podemos encarar esta produção, em que se nota maior empenho, como fruto da liberdade sentida. Além disso, a possibilidade de escolhas pessoais leva a manifestações de peculiaridades que correspondem à personalidade de cada um e imprimem originalidade aos trabalhos.

Não podemos inferir que a diferença de grau, entre primeiros e segundos semestres, tenha, como única causa, a condição de individualidade do trabalho solicitado no segundo semestre. Como sabemos, chegando ao segundo semestre os alunos estão bem mais exímios na ferramenta, a ponto de procurarem soluções de diagramação, fator que implica recursos fora do menu wiki.

De um semestre para outro, houve mudanças na posição dos alunos em relação aos links. No primeiro semestre, por representar um empecilho para um bom texto, porque exigem atenção; no segundo semestre, são creditados com a riqueza e engenho do trabalho produzido.

Para todos os alunos, os links possuem diversas funções: os internos teriam função explicativa sobre um termo, frase ou autor citado no texto principal; 
comunicação \& educação • Ano XIV • Número 2 - maio/ago 2009

os links externos proporcionariam um aprofundamento num tema ou numa biografia mais extensa sobre um autor. Os links, aos moldes da prática jornalística, podem operar no sentido de função testemunhal; com eles é possível atestar a veracidade de uma afirmação de modo a sustentar a credibilidade tão cara ao jornalismo.

Enquanto nos primeiros semestres os links são vistos como elemento estranho que força o texto a determinadas direções, no segundo são compreendidos como elementos de dupla face, pois se compõem com o texto e tanto podem levar a uma leitura dispersiva quanto podem fazer amarração e sustentar a coerência textual. Assim, os trabalhos dos segundos semestres são mais pródigos em links, e estes, por sua vez, são produto de maior reflexão sobre sua pertinência e sua função/efeito no texto.

Essa prodigalidade se repete no uso de imagens, com as quais os textos dos segundos semestres são abarrotados. E o mesmo acontece tanto na produção de 2006 quanto na de 2007 - a saber, em 2007 há mais inserção de links e imagens, particularmente no segundo semestre.

Assim, todas as observações em relação à produção de 2006 se mantiveram para a produção de 2007. No entanto, o desenvolvimento observado no segundo semestre de 2006 em relação ao primeiro do mesmo ano fica bem mais acentuado em 2007, tanto na relação entre os semestres quanto entre os anos.

Contudo, devemos ressaltar duas diferenças notórias que reverberam situações de contexto de nossa aplicação. A primeira está associada a novos modos socialmente instalados, pois diz respeito ao fato de que, ao contrário da situação no ano anterior, boa parte dos alunos de 2007 conhecia, pelo menos, a Wikipédia e seu funcionamento, sabia da existência da ferramenta wiki e alguns até haviam brincado com ela.

A segunda diferença resulta em benefícios que podem ser creditados a nossa própria experiência com o site wiki, pois conservamos as produções de 2006. Os novos alunos podiam acessá-las e ter ideias não só para o conteúdo dos artigos a serem desenvolvidos, mas também para os modos como cada formato poderia ser instalado.

Lembremos que no site wiki há uma página que registra a construção do texto, os procedimentos ou ordens oferecidas juntamente com seus formatos. Esta página de histórico dos procedimentos adotados nas produções anteriores representa grande auxílio no encontro dos caminhos a serem trilhados no que diz respeito à própria ferramenta.

Estas duas contingências situacionais levaram a um resultado ótimo quanto à rápida apreensão da ferramenta e imediata utilização de seus recursos. Em termos práticos, foi notada a ausência de solicitação de suporte da monitoria. $\mathrm{Na}$ realidade, o recurso à supervisão da monitora, a rigor, reduziu-se a dois casos. Essa supervisão operou mais como aconselhamento sobre perspectivas temáticas do que propriamente ferramentais. Enquanto no ano anterior algumas dessas habilidades surgiram apenas no segundo semestre, em 2007, já de início, os trabalhos lançaram mão de vários recursos da ferramenta, como podemos ver no exemplo a seguir. 


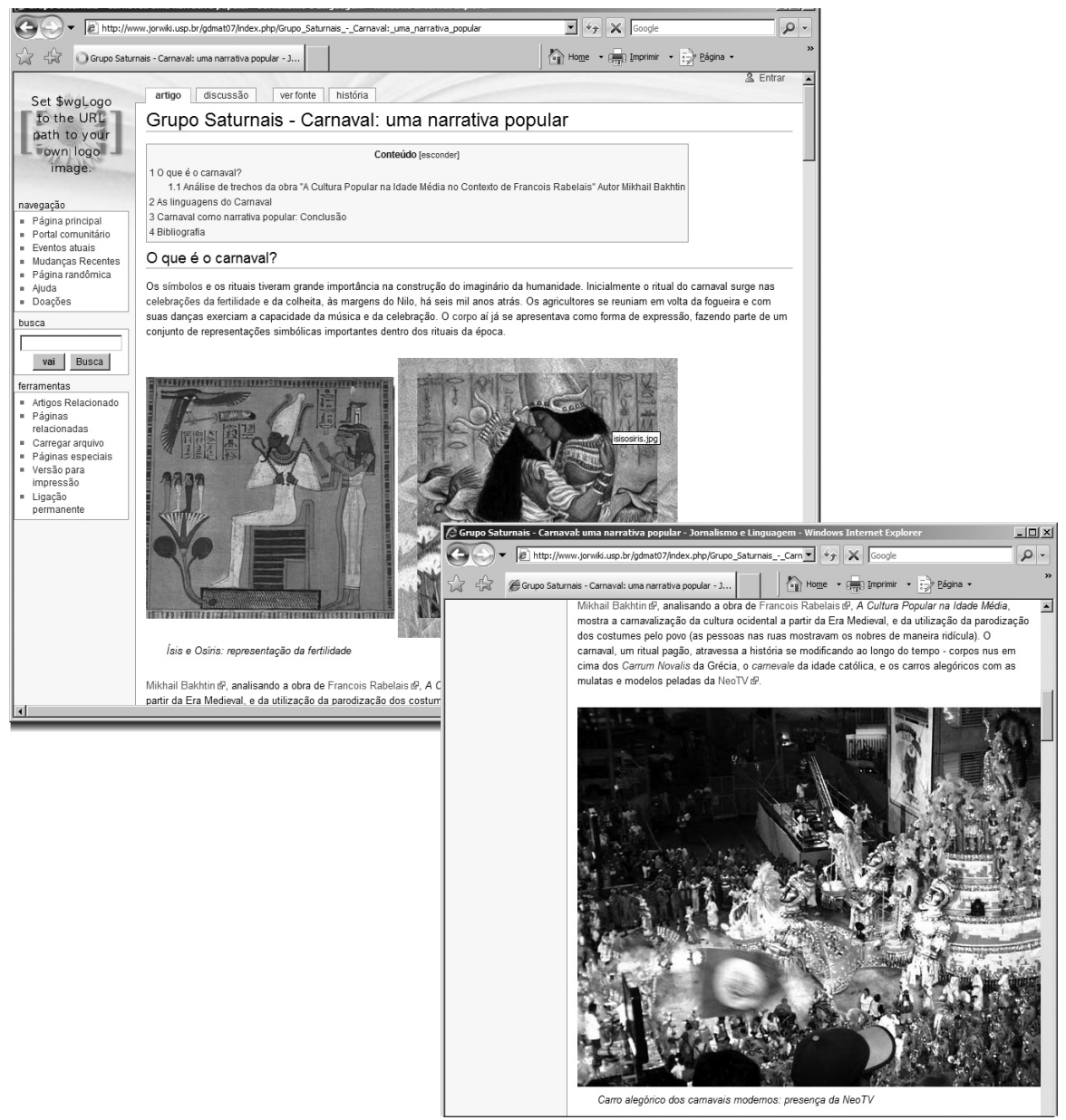

Podemos ver que o recurso à inserção de imagens foi imediato e, no caso deste trabalho em particular, um tanto eufórico. Constatamos que a paixão pela imagem foi contagiante e gerou, em alguns artigos, um excesso de imagens, apesar da pertinência destas em relação ao objeto de estudo proposto.

Este exemplo foi escolhido para demonstrar uma outra diferença encontrada, em relação ao ano anterior, que também pode ser creditada ao acesso ao site wiki, com as produções dos alunos no ano de 2006.

Os alunos desse grupo escolheram falar sobre narrativas nas festividades carnavalescas. Ocorre que o tópico Análise Estrutural da Narrativa é parte integrante do programa da disciplina ministrada no segundo semestre. Nesse caso, os alunos do primeiro semestre se adiantaram em relação ao conteúdo programático.

Portanto, o acesso aos trabalhos realizados no ano anterior foi utilizado, pelos alunos, com duas intenções ou objetivos: a apreensão das possibilidades e modos de utilização da ferramenta wiki e a inspiração nos tipos de conteúdos conceituais já expressos. Isto pôde ser observado até mesmo entre os poucos trabalhos que, em variadas formas, denotam menos empenho por parte do aluno.

Não nos preocupamos em restringir o tamanho-limite do trabalho final do segundo semestre. Como resultado, tivemos a maioria de trabalhos, em torno 
comunicação \& educação • Ano XIV • Número 2 - maio/ago 2009

de $80 \%$, bastante extensos, em comparação com os de 2006 e os do primeiro semestre de 2007. Recursos variados da ferramenta, e em maior número, estiveram presentes.

Além disso, houve, no geral, um melhor aproveitamento da propriedade de linkagem. Recorremos, como exemplo desta ocorrência, ao trabalho individual $O$ maravilhoso mundo de Harry Potter, do segundo semestre de 2007, cujos desdobramentos ilustram nossas afirmações. Este trabalho, como se apresenta em sua página principal, não passaria de uma descrição, ou introdução, ainda que bem construída, da saga de Harry Potter.

Enquanto professoras de disciplinas teóricas, não lhe concederíamos o mérito devido, pois teria deixado de cumprir com uma das tarefas solicitadas, a saber, a aplicação de conceitos, dentre os estudos de linguagem, a algum produto midiático.

Mas, ao examinarmos a pertinência dos links, chegamos à última frase inscrita em sua página principal: O mundo de Harry Potter se encaixa num tipo específico de discurso, e também se encaixa como um tipo de conto fantástico, por isso podemos, sim, fazer com ele uma Análise da narrativa com moldes em Propp e Greimas.

Ora, clicando em Análise da Narrativa, uma outra página se abre e um outro trabalho surge. A análise que segue é minuciosa e compreende nada menos que sete páginas wiki. Com isso, queremos mostrar como a construção de links foi adquirindo contornos diversificados e correspondendo, em alguns casos, à parte mais importante do trabalho, fato que elimina a possível associação entre link e nota de rodapé ou sua compreensão como mera explicação expandida.

Assim, anotamos uma progressão que, em termos de extensão, no caso da produção examinada, resultou em profundidade conceitual dos trabalhos de um semestre a outro e de um ano a outro. Também percebemos que os alunos se mostraram mais soltos, dando vazão a seus gostos e inclinações naturais. Enfatizamos a leitura dos trabalhos anteriores como base para esses efeitos, tanto assim que os alunos, em suas observações finais, a apontaram como importante fator de aprendizado.

\section{CONSIDERAÇÕES GERAIS SOBRE A EXPERIÊNCIA WIKI}

Ao final de 2007, novamente pedimos aos alunos que escrevessem sobre a experiência com a produção em site wiki.

Um exemplo dessa manifestação que nos serve a reiterar algo de nossas observações prévias: a proliferação de imagens que atinge até esse pequeno momento final em que se pedia somente uma manifestação pessoal.

A partir das observações realizadas pelos alunos, pudemos listar os tópicos que foram apontados, em relação à ferramenta wiki, e os mais recorrentes. Destacamos a compreensão de que os links constituem o ponto-chave da ferramenta. Segundo $90 \%$ dos alunos, os links demonstram que hoje a rede de conhecimento se constrói em compasso com as redes de informação, que a interconectividade 
é função básica e o saber é, enfim, constituído de múltiplas vozes e olhares. "É ele o grande ator no teatro wiki", observou um aluno sobre o link.

A importância conferida à atividade de linkagem se desdobra na ênfase dada pelos alunos às suas propriedades. Nós as arrolamos nos seguintes tópicos:

1. Os links servem para elucidar conceitos tanto para o autor que pesquisa na internet ou no texto dos colegas quanto para o leitor. Naturalmente, isso implica a possibilidade de inúmeras leituras e um grau elevado de liberdade, que, segundo um aluno, compõe "uma leitura para curiosos".

2. Os links trazem profundidade e complexidade ao texto/artigo construído e, por isso, os alunos mostraram-se francamente a favor da ferramenta wiki em comparação com um trabalho impresso tradicional.

3. Os alunos tomam conhecimento, nas aulas teóricas, do conceito de polifonia, como expresso por Mikhail Bakhtin na acepção, entre outras, de textos dentro de um texto. Foi frequente a referência a este termo, estendendo-o para a afirmação de que a ferramenta, devido a sua propriedade de link, trabalha em uníssono com os discursos que contam o mundo vivido, ou seja, sua forma coincide com a polifonia que preside nossas criações.

Ao comentarem a ferramenta como um todo, algumas atribuições também derivam da compreensão do papel dos links; outras advêm de uma apreensão mais ampla:

1. Ela estimula a criatividade, pois permite, com os links, associações inusitadas. Mas ela também convida à criatividade em virtude de suas propriedades multimídias, ou seja, por seu formato de hipertexto.

2. O resultado é um tipo de texto mais dinâmico, que os alunos qualificam como "não enfadonho", em termos de feitura e de leitura.

3. A ferramenta é de fácil apreensão, mas seu aprendizado, no todo, compreende "desaprender" formas tradicionais. A aquisição de habilidades com o wiki implica pensar diferentemente forma e conteúdo, implica "pensar wiki".

Do ponto de vista do formato implantado pelas professoras que coordenam este projeto, as observações foram as seguintes:

1. Também contribui para a qualificação de "não enfadonho" o formato de trabalho adotado com o site wiki: o texto se constrói durante certo espaço de tempo, podendo ser modificado a qualquer momento ao longo do semestre. Assim, a construção do texto se dá passo a passo e em compasso de "descoberta".

2. Dois pontos, positivamente enfatizados, foram a preservação dos textos de semestres anteriores e a possibilidade de leitura concomitante dos trabalhos, ainda em elaboração, dos colegas. O primeiro funciona como guia, ou tutorial. O segundo enriquece, inspira, complementa e gera um diálogo entre produções.

Poucos manifestaram alguma dificuldade com a ferramenta. Os que o fizeram, reconheceram não se ter dedicado o suficiente para explorar todo o seu potencial. Como já dissemos, foi baixo o número de apelos à monitora, em termos de aprendizado dos comandos do site.

A unanimidade recaiu sobre a apreciação da ferramenta, por seu papel de tirar o medo de computador, pela evolução em seu manuseio, desde o primeiro 
comunicação \& educação • Ano XIV • Número 2 - maio/ago 2009

semestre, e por sua abertura de pensamento que induz à pesquisa. De acordo com os alunos, ela é um desafio e aponta para o futuro.

Arrematando todas essas considerações, podemos afirmar que tivemos uma experiência bem-sucedida do ponto de vista de nossas expectativas em relação à progressão e à receptividade alcançada junto aos alunos.

O trabalho com a ferramenta wiki sempre nos surpreende com novos contornos, alguns impulsionados pelos alunos em suas explorações, como revela esta afirmação: "Adorei linkar e fazer conexões!!! Além disso minha mãe adorou ver 'meu texto na internet' e, ainda por cima, no wiki da USP! Ela mandou o link para as minhas avós, que também ficaram superorgulhosas... hahahaha”.

Este é um efeito wiki que não foi planejado em sua concepção como projeto pedagógico ou enquanto experiência com hipertexto. Mesmo assim, ele tem a marca da hipertextualidade e nos é caro por sua relevância como experiência de vida.

\section{REFERÊNCIAS BIBLIOGRÁFICAS}

GOMES, Mayra Rodrigues. A ferramenta wiki: uma experiência pedagógica. Comunicação \& Educação, São Paulo, CCA-ECA-USP, ano XII, n. 2, maio/ago. 2007.

\section{Endereços eletrônicos}

$<$ http://www.jorwiki.usp.br/gdmat06>

$<$ http://www.jorwiki.usp.br/gdnot06>

$<$ http://www.jorwiki.usp.br/gdmat07>

$<$ http://www.jorwiki.usp.br/gdnot07> 